\title{
What lies beneath - Skin as a window to an underlying complex disorder.
}

Piyumi Wijewickrama $^{1}$, Noel Somasundaram ${ }^{1}$, Chalukya Gunasekera ${ }^{2}$

${ }^{1}$ Endocrinology and diabetes unit, National Hospital of Sri Lanka

2Dermatology Unit, National Hospital of Sri Lanka

Correspondence Email: psw8624@gmail.com

ORCID ID: https://orcid.org/0000-0001-7260-1727

Copyright: This is an open-access article distributed under the terms of the Creative Commons Attribution License, which permits unrestricted use, distribution, and reproduction in any medium, provided the original author and source are credited (CC BY 4.0)

A 28-year-old gentleman presented with fasting hypoglycemia over last 2 months, with weight gain of $18 \mathrm{~kg}$ in last one year. He also had loss of libido and reduced shaving frequency. There were no fractures or hypercalcemic symptoms. He was extremely concerned and anxious about the widespread skin nodules and papules that he noticed over the last 5 years. His father had undergone a parathyroidectomy for a parathyroid carcinoma.On examination, he was obese with body mass index of 42 $\mathrm{kg} / \mathrm{m} 2$. Most remarkable findings were the skin lesions on his neck, axillae, chest and abdomen (Figure 1). The patient came with his father and his aunt (father's sister), who also had similar skin lesions on the abdomen (Figure 2A \& B).

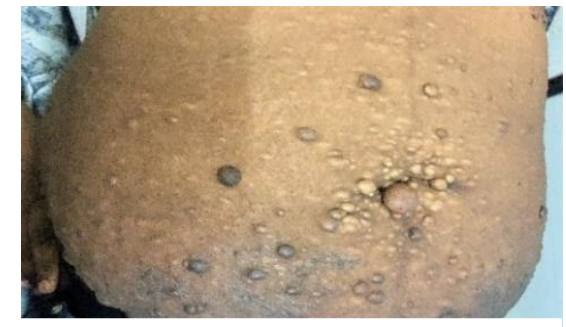

Figure 1: Patient

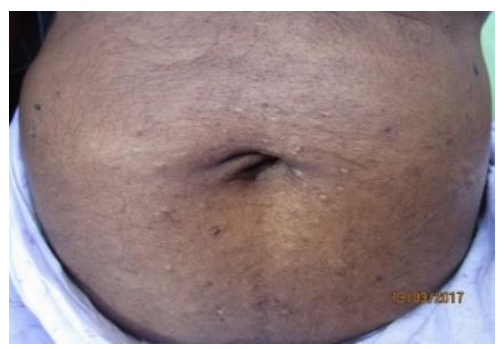

Figure 2 A - Patient's father

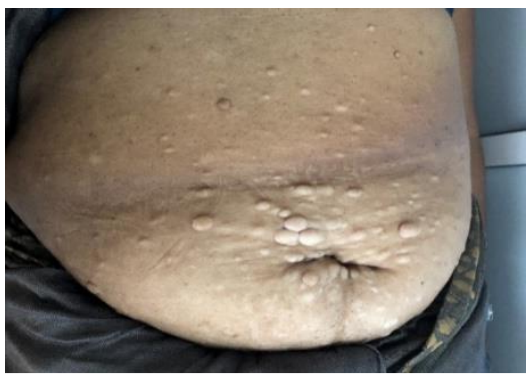

Figure 2B - Patient's aunt 
1. What is the possible overall diagnosis based on the history and examination findings?

Patient's presentation, family history and examination findings are suggestive of Multiple Endocrine Neoplasia Type 1.

2. What is the most probable diagnosis for the skin lesions and what are the other skin conditions associated with this syndrome?

\section{Collagenomas}

These are multiple, discrete, round shaped, non-tender, soft to firm, skin papules of varying sizes from $0.5 \mathrm{~cm}-1.5 \mathrm{~cm}$ and these characteristics are clinically supportive of collagenomas which are a known association with MEN1.This was confirmed histologically with the presence of haphazardly arranged thick collagen bundles in the dermis with elastic Van Gieson stain showing a reduction in elastic fiber content within the lesions. Collagenomas occur in $72 \%$ of patients with MEN1 $(1,2)$. Other associated cutaneous manifestations are, facial angiofibromas in 85\%, lipomas in 33\% and café- au - lait macules in $38 \%(1,2)$. There is no specific treatment for these cutaneous lesions.

On further investigations including 72 hour fast, the following were found (Table1)

\section{Table 1 Investigation Summary}

\begin{tabular}{lll}
\hline Investigation & Result & Normal range \\
\hline Serum fasting Insulin & $71.82 \mathrm{mu} / \mathrm{L}$ & $2.9-25$ \\
Fasting C. Peptide & $6.77 \mathrm{ng} / \mathrm{ml}$ & $0.81-3.85$ \\
Serum Calcium (ionized) & $1.4 \mathrm{mmol} / 1$ & $1-1.3$ \\
Serum Phosphate & $0.8 \mathrm{mmol} / 1$ & $0.8-1.5$ \\
Serum Parathyroid hormone level & $403 \mathrm{pg} / \mathrm{ml}$ & $10-65$ \\
Serum prolactin & $2753 \mathrm{mIU} / 1$ & $45-375$
\end{tabular}

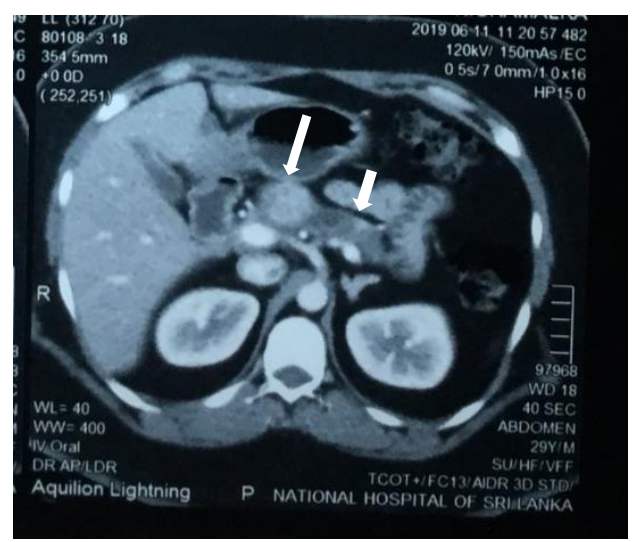

Figure 3A: CT abdomen showing 2 pancreatic lesions

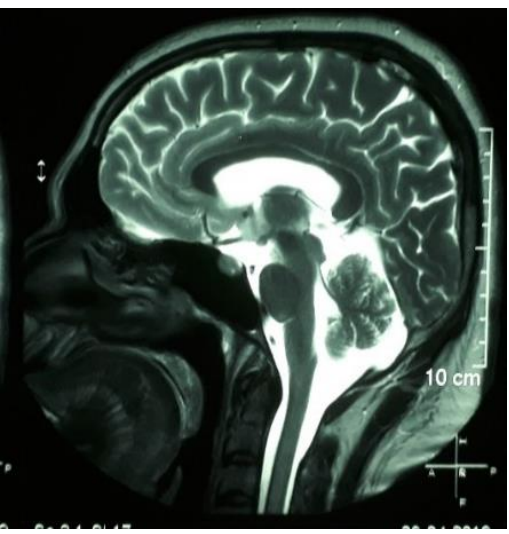

Figure 3B: MRI T2W imaging showing hyperintense pituitary lesion of $1.5 \mathrm{~mm} \times 13.2 \mathrm{~mm} \times 4.3$ $\mathrm{mm}$ size

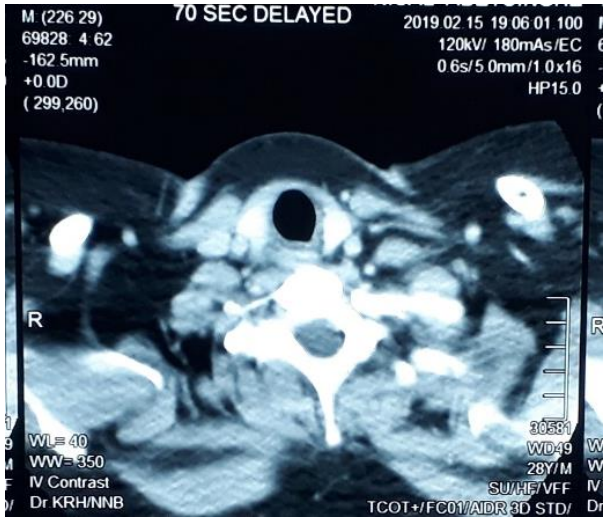

Figure 3C: CT neck showing bilateral parathyroid hyperplasia 
Other pituitary hormones were within normal range.

Imaging findings are in figures $3 \mathrm{~A}, \mathrm{~B}$, and C.

Selective Arterial Calcium Stimulation Test localized high Insulin levels to multiple arterial territories, including head, body and distal pancreas.

\section{What are the supportive features for MEN1 in this} patient?

This patient has multiple Insulinomas, parathyroid hyperplasia, microprolactinoma and skin manifestations with family history, supportive of MEN1.
MEN 1 is an autosomal dominant condition with high degree of penetrance characterized by parathyroid tumours in $90 \%$, anterior pituitary tumours in $30-40 \%$, and pancreatic neuro-endocrine tumors in 30-70\% (1). This was first described by Paul Wermer in 1954, thus giving rise to the original name "Wermer's syndrome(3). This is due to mutation of MEN1 gene localized to chromosome 11q13 which encodes the protein Menin (3). It can be diagnosed based on any one of clinical, familial or genetic criteria A diagnosis based on clinical criteria requires the presence of two out of three main tumors(1). A knowledge about the characteristic cutaneous findings in this syndrome is useful for a possible pre-symptomatic diagnosis, especially in the relatives of an index patient.

\section{References}

1. Thakker R V, Newey PJ, Walls G V, Bilezikian J, Dralle H, Ebeling PR, et al. Clinical Practice Guidelines for Multiple Endocrine Neoplasia Type 1 (MEN1). J Clin Endocrinol Metab [Internet]. 2012 Sep 1;97(9):2990-3011.

2. Vidal A, Iglesias MJ , Fernández B , Fonseca E, Cordido F 2008 Cutaneous lesions associated to multiple endocrine neoplasia syndrome type 1. J Eur Acad Dermatol Venereol 22:835-838.

3. Marini F, Falchetti A, Luzi E, et al. Multiple Endocrine Neoplasia Type 1 (MEN1) Syndrome. 2008 Jul 18 [Updated 2008 Aug 9]. In: Riegert-Johnson DL, Boardman LA, Hefferon T, et al., editors. Cancer Syndromes [Internet]. Bethesda (MD): National Center for Biotechnology Information (US); 2009. 